\title{
Effects of Temperature and Diet on the Growth Rate of Year 0 Oyster Toadfish, Opsanus tau
}

\author{
A. F. MENSINGER ${ }^{1,2, *}$ AND M. E. TUBBS ${ }^{1}$ \\ ${ }^{1}$ Marine Biological Laboratory, Woods Hole, Massachusetts 02543; and ${ }^{2}$ Biology Department, \\ University of Minnesota-Duluth, 10 University Dr., Duluth, Minnesota 55812
}

\begin{abstract}
The effects of temperature and diet on the growth of captive year 0 specimens of Opansus tau were examined for two consecutive year classes. The 2001 year class was raised at about 23,26 , or $29^{\circ} \mathrm{C}$ and provided with live brine shrimp, frozen butterfish and squid, or commercial food pellets (45\% protein, $19 \%$ fat, and $3 \%$ fiber) three times per week. Maximal growth was achieved with the pellet diet, and fish raised at $29^{\circ} \mathrm{C}$ attained the highest mean wet weight (84.0 $\mathrm{g} \pm 14.6 \mathrm{~g} \mathrm{SE})$ and fastest instantaneous relative growth rate (IRGR, $1.79 \%$ body weight/d). The 2002 year class was raised on the same pellet diet at $31.5^{\circ} \mathrm{C}$ and fed 3, 5, or 7 times per week. Although more frequent feedings led to significantly greater mean wet weight in the first half of the year, by month 12 there was no significant difference between the three feeding frequencies. These fish weighed approximately $68 \mathrm{~g}$ and had an average IRGR of $1.74 \%$ body weight/d. The pellet diet during both years was correlated with high survival $(>75 \%)$.
\end{abstract}

\section{Introduction}

The oyster toadfish, Opsanus tau Linnaeus, is a benthic marine fish that inhabits the eastern coast of the United States. Although historically shunned by recreational and commercial fisherman, the oyster toadfish has been the focus of scientific study since its development was first outlined by Ryder (1887). Males will establish nesting territories in the spring and acoustically attract females to their nests. After spawning, males guard the nest until the freeswimming juveniles detach several weeks later.

The male toadfish produces sound by contracting the sonic muscle surrounding its swim bladder. This feature has

Received 3 October 2005; accepted 8 December 2005.

* To whom correspondence should be addressed. E-mail: amensing@ d.umn.edu led to a number of investigations on sound generation (Gray and Winn, 1961; Winn, 1972), reproductive ecology (Fine, 1978; Fine and Lenhardt, 1983), auditory physiology (EddsWalton et al., 1999; Edds-Walton and Fay, 2003), and muscle kinetics (Rome and Klimov, 2000; Young and Rome, 2001; Young et al., 2003). The large flat head of the toadfish allows access to vestibular end organs, enabling the fish to serve as a model for studies on equilibrium and balance both on earth (Mensinger et al., 1997, 2000; Mensinger and Highstein, 1999; Rabbitt et al., 2001) and during two space shuttle missions (Boyle et al., 2001).

The scientific demand for toadfish has spawned what may be the world's smallest fishery. Toadfish are traditionally a by-catch of the Cape Cod eel fishery, and landings have rarely exceeded a few thousand fish (about $2000 \mathrm{~kg}$ ); fewer than 500 fish are currently needed to meet yearly demand. However, in recent years, local toadfish populations appear to be in decline (E. Enos, Marine Biological Laboratory, pers. comm.), and captive stocks have suffered from several outbreaks of disease (Wenuganen et al., 1997; Smolowitz and Bullis, 1997; Smolowitz et al., 1998; Smolowitz, Hanley, and Tubbs, Marine Biological Laboratory; unpubl.) that have resulted in a critical shortage of experimental animals for investigators. In addition, a commercial fishery has begun in the mid-Atlantic states, targeting the fish for consumption in Asian markets (M. Feigenbaum, South Shore Trading Co., pers. comm.), and its expansion could further jeopardize stocks.

Despite a century of investigation, distribution of the fish during the fall and winter, natural growth rates, attainment of sexual maturity, and optimal culturing conditions remain unknown for toadfish in the Cape Cod area of the eastern U.S. coast. A mariculture program was initiated in the summer of 1998 to assess the feasibility of culturing $O$. tau to meet experimental demands and to eventually reduce 
pressure on the wild stocks (Tang et al., 1999; Mensinger et al., 2001; Rieder and Mensinger, 2001). The fish proved exceptionally hardy in culture, with $70 \%$ survival after 2 years. However, despite maintenance at above ambient temperatures, the fastest growing fish averaged only $10 \mathrm{~cm}$ standard length and $40.5 \mathrm{~g}$ after 24 months in captivity. As most of the scientific demand is for adult fish at least $25 \mathrm{~cm}$ and $400 \mathrm{~g}$, those growth rates rendered the project economically infeasible (Mensinger et al., 2003). In the present study, the effects of warmer temperatures, diet, and feeding frequency on growth in age 0 toadfish were examined.

\section{Materials and Methods}

\section{Collection and spawning}

In June 2001, toadfish nests $(n=5)$ with guardian males were collected in the Waquoit Bay Estuary, Massachusetts, and transported to the Marine Resources Center of the Marine Biological Laboratory (MBL), Woods Hole, Massachusetts. The toadfish eggs had hatched prior to collection; however, the small unpigmented larval fish remained attached to the nest. Each nest, and its guardian male, was placed in an individual 160-1 flow-through aquarium with running seawater at $20^{\circ} \mathrm{C}$. As the larval fish began to detach from the nests (within $30 \mathrm{~d}$ of collection), the guardian males were removed.

In 2002, spawning took place within the confines of a saltwater pond at the Environmental Systems Laboratory on the Quissett campus of the Woods Hole Oceanographic Institute, Woods Hole, Massachusetts. Gravid females that were captured in early June from Hamblin Pond, Waquoit Bay, Massachusetts, were added to the pond containing overwintered male toadfish. Bricks were provided for nesting sites, and spawning ensued within the week. The nests and guardian males were left undisturbed until the larval fish were about to detach from the nest (Fig. 1). At that point, the larval fish were removed from the substrate, transported to the MBL, and placed in shallow seawater trays $\left(1-\mathrm{m}^{2}\right.$ area; $7-\mathrm{cm}$ water depth) with ambient flowthrough seawater.

\section{1 year class}

Recently detached fish $(n=90)$ from a single nest were removed from their home aquarium during the first week of July and distributed equally among nine 40-1 glass aquaria, resulting in an initial density of $9 \mathrm{fish} / 0.1 \mathrm{~m}^{2}$. Each tank was equipped with an overhead 17-W fluorescent light that maintained the animals on a light/dark photoperiod of 14 : 10. During the day, the tanks also received overhead illumination from room fluorescent lights and indirect sunlight from nearby windows. Large rocks and PVC pipe served as habitat. Fish were maintained at $23{ }^{\circ} \mathrm{C}, 26{ }^{\circ} \mathrm{C}$, or $29^{\circ} \mathrm{C}$ in recirculating seawater systems equipped with mechanical, biological, and ultraviolet filtration. Distilled water was added to replace water lost to evaporation, and 50\% seawater changes were made at least monthly. An additional 140 fish served as controls and were kept under the conditions of the previous mariculture study (Mensinger et al., 2003). The control fish were divided equally among four shallow $(7-\mathrm{cm}$ water depth) fiberglass aquaria $(0.8 \times 1.3 \mathrm{~m})$ and provided with filtered $20{ }^{\circ} \mathrm{C}$ flow-through seawater. The density for the control fish ranged from 30 to $35 \mathrm{fish} / \mathrm{m}^{2}$ for the 12 month study.

Standard length was determined to the nearest $0.1 \mathrm{~cm}$ by placing small fish $(<10 \mathrm{~cm})$ on a fine-mesh screen superimposed over a ruler, and larger fish $(\geq 10 \mathrm{~cm})$ in a $\mathrm{V}$-shaped wooden trough with attached ruler. The fish were then placed on an absorbent towel to remove excess moisture and transferred to an analytical balance (Denver Instrument Company TR-4102D) to determine wet body weight.

Fish at each temperature were maintained on one of three diets: live, frozen, or pellet. All fish were fed three times per week. For the live diet (LD), adult Artemia were presoaked in Super Selco vitamin solution $\left(\sim 1 \mathrm{ml}^{-1}\right.$ of seawater for $1 \mathrm{~h}$ ) and added to the tanks during the course of an hour until fish ceased feeding. The frozen diet (FD) consisted of chopped butterfish (Peprilus triacanthus Peck) and squid (Loligo pealeii). The pellet diet (PD) consisted initially of small pieces of chopped squid rolled in ground salmon pellets (Silver Cup: $45 \%$ protein, 19\% fat, and 3\% fiber). After 2 to 3 weeks, fish were able to consume crumbled or intact 1-mm pellets, and the squid supplement was discontinued. At 10 months, fish were switched to $3-\mathrm{mm}$ pellets. Fish on frozen and pellet diet initially were hand-fed by placing the food on a wire and waving it near their mouths. After 2 to 3 weeks, fish began foraging, eliminating the need for hand-feeding. The FD and PD fish were allowed to forage for about $2 \mathrm{~h}$ before uneaten food was siphoned from the tanks. Control fish were raised initially on the LD and switched to the PD as soon as they would spontaneously forage for pellets (about 4 weeks). When any experimental fish exceeded $25 \mathrm{~g}$, it was transferred to a shallow (water depth $7 \mathrm{~cm}), 1-\mathrm{m}^{2}$ fiberglass tank.

\section{2 year class}

Fish began detaching from the nests at the end of July and were placed in shallow fiberglass trays where they were provided with ambient seawater (range 20 to $22{ }^{\circ} \mathrm{C}$ ). Freeswimming fish were randomly mixed from at least five females and multiple males. Fish were fed four to five times weekly with live adult Artemia that had previously been dipped in Super Selco. During the first week of September, 65 fish $(\sim 2.4 \mathrm{~cm}$ standard length and $0.4 \mathrm{~g})$ were transferred to the 40-1 aquaria vacated by the 2001 year class and provided with recirculating seawater heated to $31.5^{\circ} \mathrm{C}$. The initial density in these aquaria ranged from 7 to $9 \mathrm{fish} / \mathrm{m}^{2}$. 


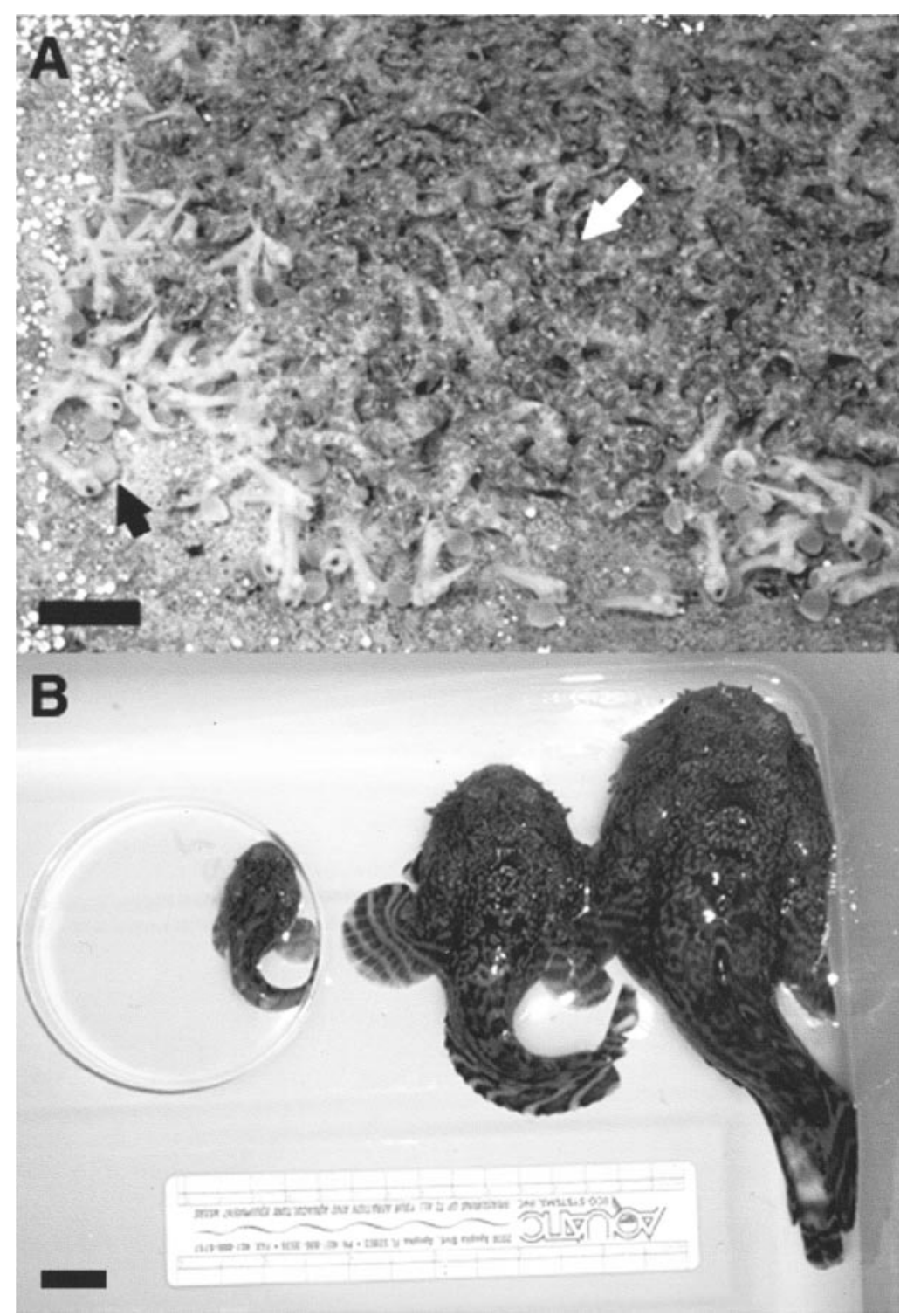

Figure 1. (A) Inverted toadfish nest containing attached juvenile fish. The black arrow points to the partially absorbed yolk sac that anchors the juvenile fish to the roof of the nest. The fish at this stage are largely unpigmented except for the eyes. The white arrow is surrounded by larger, pigmented juveniles that spawned 2 weeks earlier. These fish detached within 2 days of the photo. Scale bar $=1 \mathrm{~cm}$. (B) Toadfish at 10 months following detachment. All fish were raised on the pellet diet and fed three times per week. The fish on the left was raised at $23{ }^{\circ} \mathrm{C}$, the middle fish at $26{ }^{\circ} \mathrm{C}$, and the fish on the right at $29{ }^{\circ} \mathrm{C}$. Scale bar $=2 \mathrm{~cm}$.

After the transfer, all fish were fed pellets exclusively. Group $3 \times(n=2$ tanks, 14 fish total $)$ was fed three times per week; group $5 \times(n=3 ; 24$ fish $)$ five times per week; and group $7 \times(n=3 ; 27$ fish $)$ daily. Control fish $(n=4$, $100 \mathrm{fish}$ ) of similar size were also transferred at the same time and divided equally among four shallow (water depth $7 \mathrm{~cm}$ ), $1-\mathrm{m}^{2}$ fiberglass tanks (density of $25 \mathrm{fish} / \mathrm{m}^{2}$ ). The controls were maintained at $22.5{ }^{\circ} \mathrm{C}$ and fed pellets three times per week. In February, the largest fish $(8.8$ to $10.0 \mathrm{~cm}$ standard length; 19 to $31 \mathrm{~g}$ ) were transferred to a 2000-1 recirculating system and segregated by partitions according to their group and feeding frequency, resulting in densities ranging from 10 to $20 \mathrm{fish} / \mathrm{m}^{2}$. All other care and monitoring were identical to those for the 2001 year class.

\section{Statistical analysis}

Statistical analysis was performed with GraphPad Software ver. 3.0 (San Diego). Samples were tested for normality using the method of Kolmogorov and Smirnov. Bartlett's test was then used to assure that the standard deviations of the groups were sufficient for parametric statistical 
tests. For the 2001 class, unpaired student's $t$ tests were used to determine significant differences between each treatment and the controls. One-way analysis of variance (ANOVA) was used to compare the wet weights of the different diets. For 2002, ANOVAs were used to determine differences among the replicates.

Microsoft Excel was used to fit and compare linear, exponential, and power function equations to the weight data for each group. The resulting correlation coefficient $(r)$ values obtained from the curve fitting were used to determine which equation best described the data. Instantaneous relative growth rates (percent increase in body weight per day; IRGR) were calculated according to the equation

$$
\operatorname{IRGR}=[\ln (W 2)-\ln (W 1)] \times(100) \times t^{-1},
$$

where $\ln (W 1)$ and $\ln (W 2)$ are the natural logs of weight measurements 1 and 2, and $t$ is the time, in days, between measurements (Chapman, 1971).

\section{Results}

More than $97 \%$ percent of larval fish successfully completed development in the laboratory and detached from the nests in both years. Fish maintained on the live Artemia diet (LD) experienced over $60 \%$ mortality in the first year, and only the fish at $23{ }^{\circ} \mathrm{C}$ and $29{ }^{\circ} \mathrm{C}$ survived. The frozen diet (FD) toadfish suffered steady losses (40\%) through day 240, then declined rapidly and were eliminated by day 300 . The experimental fish maintained on the pellet diet (PD) in 2001 had greater than $90 \%$ survival that was distributed equally over the three temperature regimes. The PD control fish had a survival of $84 \%$. Relatively high survival continued with the pellet diet in 2002, with survival values exceeding $73 \%$ ( $85 \%$ overall) for all feeding frequencies treatment groups (Table 1; Fig. 2).

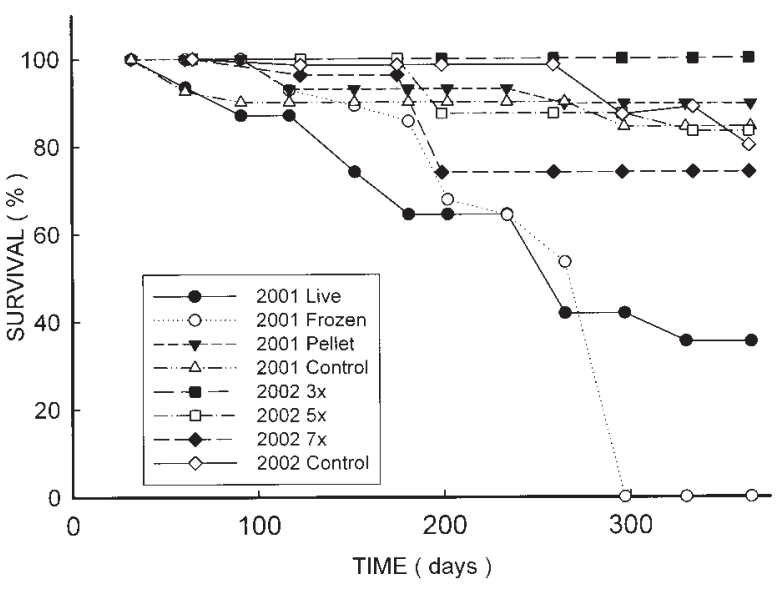

Figure 2. Toadfish survival ( $\%$ of original cohort) is plotted versus time (days) from detachment from nest. For the 2001 experimental fish, all temperatures were combined and the legend indicates diet. The 2001 control fish were maintained at $20.5^{\circ} \mathrm{C}$ and fed pellets three times per week. During 2002, all experimental fish were raised at $31.5{ }^{\circ} \mathrm{C}$ and the legend indicates feeding frequency. The 2002 control fish were raised at $22.0^{\circ} \mathrm{C}$ and fed pellets three times per week.

\section{1 year class}

The average size of recently detached fish was $1.4 \mathrm{~cm}$ (standard length) and $0.1 \mathrm{~g}$. Minimal growth was achieved on the LD, with these fish averaging less than $2 \mathrm{~g}$ at the end of the year. In all experimental PD treatments, fish were significantly heavier than in the PD control $(t$ test: $P<$ 0.05); $29^{\circ} \mathrm{C}$ fish attained the greatest mean wet weight $(84.0$ g). Growth trajectories for the PD had the best fit to a power function $\left(y=a X^{b}\right)$ throughout the year, and the $29^{\circ} \mathrm{C} \mathrm{PD}$ had the highest instantaneous relative growth rate (IRGR) (1.79\% bodyweight per day [\% BW/d]) from detachment through 12 months (Table 1; Fig. 3a).

Table 1

Toadfish growth

\begin{tabular}{|c|c|c|c|c|c|c|}
\hline Year class & $\begin{array}{l}\text { Weekly } \\
\text { temperature* }\end{array}$ & $\begin{array}{c}\text { Diet } \\
\text { (feeding frequency/week) }\end{array}$ & $\begin{array}{l}\text { Standard length* } \\
(\mathrm{cm})\end{array}$ & Wet weight $(\mathrm{g})^{*}$ & $\begin{array}{c}\% \text { Survival } \\
(n) \dagger\end{array}$ & $\begin{array}{c}\text { IRGR } \ddagger \\
(\% \mathrm{BW} / \mathrm{d})\end{array}$ \\
\hline \multirow[t]{6}{*}{2001} & $22.5 \pm 0.1(20.0-24.7)$ & Live $(3 x)$ & $4.4 \pm 0.4(3.3-5.1)$ & $1.9 \pm 0.5(1.0-3.2)$ & $40.0(10)$ & 0.76 \\
\hline & $28.8 \pm 0.1(25.0-32.3)$ & Live $(3 x)$ & $4.3 \pm 0.1(3.8-0.1)$ & $1.5 \pm 0.2(1.0-2.3)$ & $50.0(10)$ & 0.69 \\
\hline & $20.5 \pm 0.1(19.8-21.1)$ & Pellet (3x) (control) & $7.2 \pm 0.1(5.2-10.9)$ & $12.2 \pm 0.5(3.4-27.4)$ & $84.0(140)$ & 1.17 \\
\hline & $22.5 \pm 0.1(20.0-24.7)$ & Pellet $(3 x)$ & $8.6 \pm 0.6(5.8-12.0)$ & $23.0 \pm 4.6(6.6-51.0)$ & $100.0(10)$ & 1.44 \\
\hline & $26.1 \pm 0.1(25.0-28.6)$ & Pellet (3x) & $11.4 \pm 0.6(8.5-14.4)$ & $53.7 \pm 8.3(18.9-100.0)$ & $90.0(10)$ & 1.67 \\
\hline & $28.8 \pm 0.1(25.0-32.3)$ & Pellet $(3 x)$ & $13.3 \pm 0.8(10.1-16.3)$ & $84.0 \pm 14.6(36.1-156.0)$ & $77.8(9)$ & 1.79 \\
\hline \multirow[t]{4}{*}{2002} & $21.7 \pm 0.2(20.5-23.0)$ & Pellet (3x) (control) & $7.2 \pm 0.1(5.6-9.3)$ & $10.8 \pm 0.4(4.5-22.3)$ & $73.0(100)$ & 1.07 \\
\hline & $31.5 \pm 0.1(26.2-34.3)$ & Pellet $(3 x)$ & $12.6 \pm 0.3(10.0-14.0)$ & $70.1 \pm 6.2(29.3-129.3)$ & $100.0(14)$ & 1.75 \\
\hline & $31.5 \pm 0.1(26.2-34.3)$ & Pellet (5x) & $12.7 \pm 0.4(9.0-14.8)$ & $65.8 \pm 5.9(23.5-116.2)$ & $83.3(24)$ & 1.73 \\
\hline & $31.5 \pm 0.1(26.2-34.3)$ & Pellet $(7 x)$ & $12.7 \pm 0.3(10.3-14.6)$ & $68.8 \pm 4.5(31.6-124.9)$ & $74.1(27)$ & 1.74 \\
\hline
\end{tabular}

* Values are means \pm 1 standard error. Parentheses indicate range.

$\dagger n=$ number of fish at start of experiment.

\$IRGR = Instantaneous Relative Growth Rate. Calculated from day 0 (detachment) to day 365. 


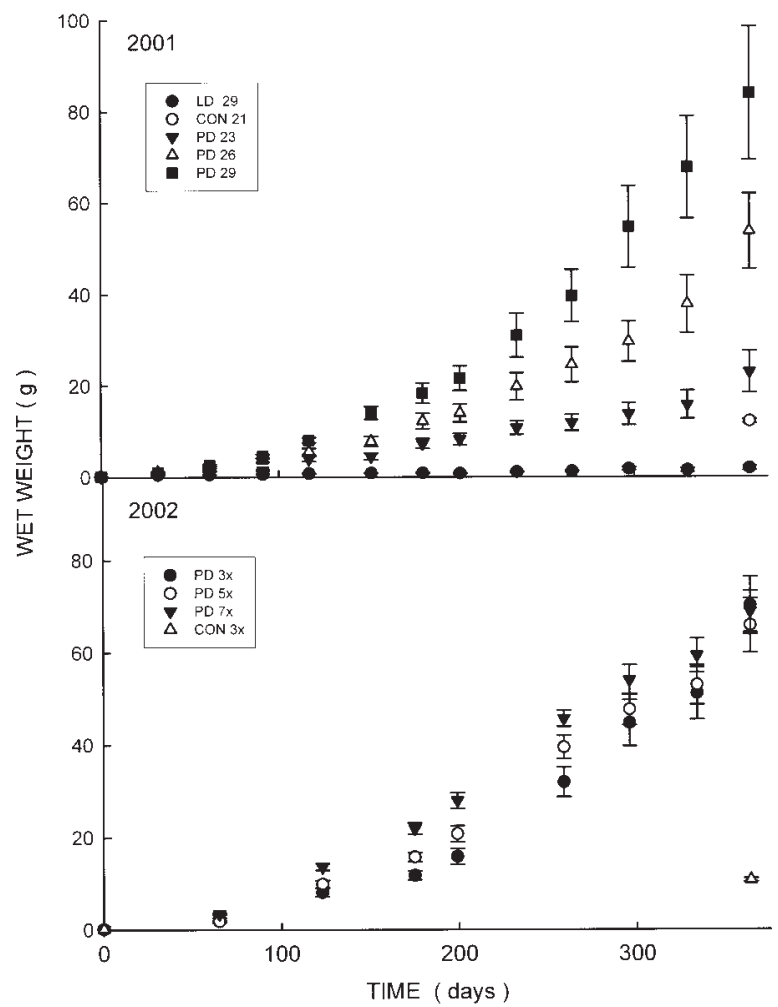

Figure 3. The mean wet weights of toadfish in 2001 (top) and 2002 (bottom) are plotted versus time (days) following detachment from the nest. The legend for 2001 indicates diet (LD, live diet; PD, pellet diet) and the temperature at which the experimental fish were cultured. The legend for 2002 indicates the feeding frequency per week for the experimental groups. Control fish $(\mathrm{CON})$ only were weighed at the beginning and the end of the study. The control fish were fed pellets three times per week; these fish were maintained at $20.5^{\circ} \mathrm{C}$ in 2001 and at $21.7^{\circ} \mathrm{C}$ in 2002 . Error bars $=1$ standard error.

\section{2 year class}

All three feeding treatments displayed steady growth throughout the year: these fish reached about $68 \mathrm{~g}$ and had an average IRGR of $1.74 \%$ body weight/d. The $7 \mathrm{x}$ fish initially showed faster growth and were significantly heavier than both the $3 \mathrm{x}$ and $5 \mathrm{x}$ fish at 65 days (ANOVA: $P<0.05$ and 0.001 , respectively). This difference persisted through day 199 for the 5x fish (ANOVA: $P<0.01$ ) and day 259 for the 3x fish (ANOVA: $P<0.01$ ); however, by day 296 there was no significant difference between the treatments. At day 365 , the $3 \mathrm{x}$ fish $(70.1 \mathrm{~g})$ slightly exceeded the $7 \mathrm{x}(68.8 \mathrm{~g})$ and $5 \mathrm{x}(65.7 \mathrm{~g})$ fish in weight (Fig. $3 b)$. At all feeding frequencies, the treatment groups were significantly heavier than the controls (ANOVA; $P<0.01$ ). The growth rates were best fit by a power function $\left(y=a X^{b}\right)$ throughout the year, and the maximal IRGR was seen in the $3 \mathrm{x}$ fish at $1.75 \% \mathrm{BW} / \mathrm{d}$. Although all three feeding frequencies at $31.5^{\circ} \mathrm{C}$ were heavier than the $200123^{\circ}$ and $26{ }^{\circ} \mathrm{C}$ PD, they remained less than the $29^{\circ} \mathrm{C}$ PD (Fig. 4).

\section{Discussion}

The goal of the toadfish mariculture project was to provide researchers with a year-round supply of healthy fish and thereby reduce reliance on local populations. Most researchers require fish with a minimum standard length of $25 \mathrm{~cm}$ and a weight of 400 to $500 \mathrm{~g}$. A previous mariculture effort demonstrated that toadfish can be successfully raised in captivity at 15 or $20^{\circ} \mathrm{C}$. However, relatively slow growth rates (50 g after 2 years) made the method tested impractical (Mensinger et al., 2003). The current study examined the effect of higher temperatures, diet, and feeding frequency to determine whether the fish could be grown at faster rates.

\section{Survival}

The toadfish proved hardy despite being raised at temperatures well above ambient (e.g., the average weekly temperature of ambient water at the MBL in 1999 was 11.9 $\left.{ }^{\circ} \mathrm{C}\right)$. Fish survived well on the pellet diet regardless of temperature, with survival ranging from $73 \%$ to $100 \%$ (87\% overall). Fish raised exclusively on the brine shrimp diet grew slowly and suffered greater than 50\% mortality. Although the frozen diet promoted faster growth than the live diet, it eventually proved unfavorable as fish failed to survive past 300 days. Fish were kept under similar conditions and the pellet fish thrived at the three temperatures; thus it appears that diet was the mitigating factor in the decline of the fish fed the frozen diet.

At first glance, the results from the frozen diet seemed paradoxical because both wild adult and maricultured toadfish have routinely been maintained on a frozen/prepared food diet for up to 4 years in captivity (Mensinger, unpubl. data). However, due to declining squid catches, the frozen

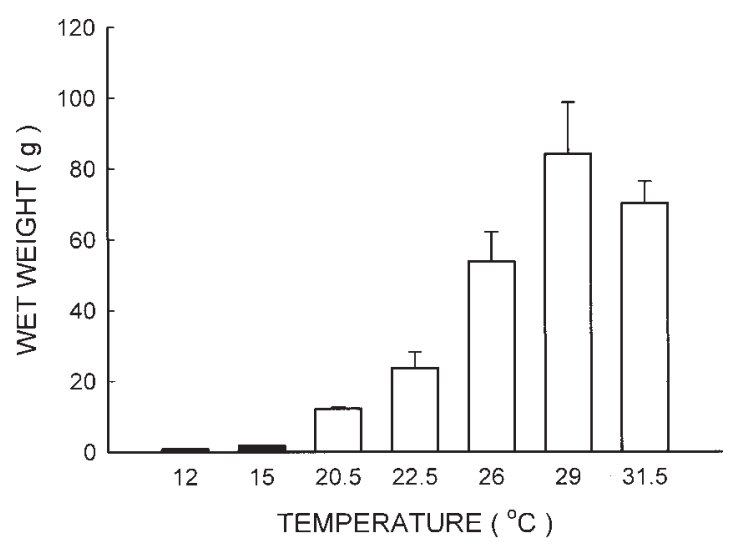

Figure 4. The bars represent mean wet weight of toadfish at 12 months after detachment. The labels indicate the average temperature at which the fish were cultured. The 12 and $15{ }^{\circ} \mathrm{C}$ fish (solid fill) were raised on a squid diet, and the data is taken from Mensinger et al. (2003). The remaining treatments (open fill) were raised on the pellet diet. Error bars $=1$ standard error. 
diet in 2001 was more than $50 \%$ butterfish. Post-mortem examination concluded that the toadfish were suffering from nutritional myopathy presumably due to the high fat content of the butterfish (Smolowitz, Hanley, and Tubbs, Marine Biological Laboratory, unpubl.).

\section{Density}

Fish density is an integral factor in any culture initiative because the cost benefits of increasing the culture density must be balanced against the health and growth rates of the organism. For benthic species such as the toadfish, the substrate area limits growth more often than tank volume does, because these fish rarely use mid-depth or near-surface waters. Previous studies had shown no significant difference in growth of year 0 toadfish raised at densities between 10 and $87 \mathrm{fish} / \mathrm{m}^{2}$ (Mensinger et al., 2003). Therefore, the culture densities in the current study (maximum 90 fish $/ \mathrm{m}^{2}$ ) probably did not affect growth rates. However, as the fish grow larger in future years, these densities may have to be reduced.

\section{Temperature}

The oyster toadfish is distributed widely along the Atlantic seaboard of the United States from Cape Cod, Massachusetts, to Florida, with conspecifics reported in water temperatures of at least $28{ }^{\circ} \mathrm{C}$ (Fine, 1978). Although able to tolerate wide temperature variations, the fish is considered a cold-water species in the Cape Cod area. Water temperatures from the primary collection area in Hamblin Pond, Waquoit Bay, Massachusetts, ranged from 12 to 25 ${ }^{\circ} \mathrm{C}$ during the primary breeding and egg development season (May-June), with freezing temperatures reported in the winter and highs of $27{ }^{\circ} \mathrm{C}$ in summer (Waquoit Bay National Estuarine Research Reserve water quality data, Hamblin Pond). The ambient water temperature at the MBL ranged from 5 to $23{ }^{\circ} \mathrm{C}$ during the course of the study.

The initial mariculture effort was conducted with a maximum temperature of $20{ }^{\circ} \mathrm{C}$ out of concern for continual elevated temperatures on toadfish survival (Mensinger et al., 2003). Captive adult toadfish routinely have fared better at 12 to $15{ }^{\circ} \mathrm{C}$ than at $20{ }^{\circ} \mathrm{C}$ (Mensinger, pers. obs.). However, due to the slow growth at $20{ }^{\circ} \mathrm{C}$, higher temperatures were employed in this study to stimulate faster growth. As the maximal growth was correlated with the highest temperature in 2001, the temperature was raised about $2.5{ }^{\circ} \mathrm{C}$ during the succeeding year to determine whether growth rate could be further accelerated. All fish fed the pellet diet at temperatures from 26 to $31.5{ }^{\circ} \mathrm{C}$ were heavier after 1 year than fish raised for 2 years on a squid diet at $20{ }^{\circ} \mathrm{C}$, indicating that toadfish can be successfully cultured at average temperatures well above ambient. However, maximum growth was observed at $29{ }^{\circ} \mathrm{C}$; fish raised at 26 and $31.5^{\circ} \mathrm{C}$ exhibited slower weight gain. Further re- finement is needed to determine whether maximal growth peaks at $29{ }^{\circ} \mathrm{C}$ or at another temperature between 26 and $31.5^{\circ} \mathrm{C}$.

Diet

The large yolk of the toadfish eggs provides substantial nourishment and enables extended development in the nest, producing detached juveniles that resemble adults in everything but size. The juveniles possess a voracious appetite for moving prey such as brine shrimp, mysids, small crabs, or fish, which obviates the specialized transitional foods that cultured species commonly need. Unfortunately, recently detached fish display little inclination to forage for non-motile processed food or pellets. The fish readily consumed small pieces of squid or pellets that were presented to them, so movement rather than palatability appeared to be the issue. In earlier culture efforts, fish had to be fed live brine shrimp for as long as 3 months before they would forage on inert feed. Although hand-feeding eliminated the brine shrimp phase, such an effort would be infeasible in large-scale cultures. To circumvent this bottleneck, small submersible water pumps were placed in each tank and activated when food was presented. The resultant movement of the squid or small pellets induced feeding in recently detached fish. Within a few weeks, the pumps were removed as the fish learned to forage for the pellets.

Both the pellet and frozen diet proved significantly better for growth than live brine shrimp. Although the frozen diet was moderately successful in encouraging growth, its high fat content resulted in nutritional myopathy and proved detrimental. The relatively rapid growth and high survival of fish raised on the pellets indicates that this diet meets the nutritional needs of the fish. The pellet diet consisted of $45 \%$ protein, $19 \%$ fat, and 3\% fiber. Current studies are examining different diet compositions to determine whether changes in the protein composition will affect growth.

\section{Feeding frequency}

Feeding frequency has been documented to influence fish growth. Yellowtail flounder (Limanda ferruginea Storer) display optimal weight gain when fed twice daily (Dwyer $e t$ al., 2002); however, the estuarine grouper (Epinephelus tauvina Forsskall) has maximal growth when fed every other day (Thia-Eng and Seng-Keh, 1978). Based on field observations, $15 \%$ to $60 \%$ of toadfish had empty stomachs, indicating that wild toadfish do not feed daily (Schwartz and Dutcher, 1963; Wilson et al., 1982). Captive adults, fed to satiation with live feeder fish or squid, may refuse food for up to a week. The 2002 toadfish that were fed daily grew faster initially than fish fed 3 or 5 times per week; by the end 
of the year, however, there was no weight difference between the feeding frequencies.

Growth may also have been affected by sexual maturation. Several year 0 females became gravid in late spring, and a number of unfertilized eggs were observed in the tanks throughout June and July. Unfortunately, a reliable method for sexing "non-gravid" juvenile toadfish remains to be developed. Size is more important than gender for most investigators; thus, if males prove to be faster growers, the ability to segregate the fish by gender could lead to the more rapid attainment of research-sized fish.

\section{Toadfish culture}

About 500 healthy adult toadfish are currently needed each year for scientific demand. Several of the $29^{\circ} \mathrm{C} 2001$ fish exceeded $300 \mathrm{~g}$ by the end of 24 months despite being cultured at cooler temperatures $\left(23\right.$ to $25{ }^{\circ} \mathrm{C}$ ) during their second year, indicating that if these growth rates continue, fish weighing 400 to $500 \mathrm{~g}$ will be attainable within 3 years (Mensinger, unpubl.). The demand for fresh fish has already established toadfish as a niche market in Asian restaurants in the northeastern United States because they can be maintained in restaurant aquaria and kept alive until selected by diners. Nonetheless, catches remain seasonal, with most landings in spring and fall, and culturing would allow yearround availability. For commercial aquaculture, the toadfish presents several distinct advantages: it breeds easily in captivity, has high survival rates, does not require specialized food, and can be cultured at relatively high densities. As the natural growth rates of toadfish appear slow (Mensinger et al., 2003), unregulated and indiscriminate harvesting of this species could significantly impact local populations, as could already be the case in Cape Cod. A viable culture program would alleviate pressures on wild stocks and provide researchers and commercial markets with a year-round supply of fish.

\section{Acknowledgments}

Thanks to Ed Enos for furnishing data on the history of toadfish collections at the Marine Biological Laboratory. Leila Rieder and Bill Mebane provided invaluable help in establishing and maintaining the aquaria. Chris Weidman and Kelly Chapman from the Waquoit Bay National Estuarine Research Reserve supplied logistics and support for our field collecting sites. Larry Rome contributed valuable assistance in renovating the artificial pond used in 2002. Support was provided by the Marine Models in Biological Research Program, the University of Minnesota Grant in Aid, the NASA Life Science Fellowship, the MBL Associates Fellowship, and NIH grant DC01837.

\section{Literature Cited}

Boyle, R., A. F. Mensinger, K. Yoshida, S. Usui, A. Intravaia, T. Tricas, and S. M. Highstein. 2001. Neural readaptation to Earth's gravity following return from space. J. Neurophysiol. 86: 2118-2122.

Chapman, D.W. 1971. Production. Pp. 199-214 in Methods for Assessment of Fish Production in Fresh Waters, W. E. Ricker, ed. IBP Handbook No. 3. Blackwell, Oxford.

Dwyer, K. S., J. A. Brown, C. Parrish, and S. P. Lall. 2002. Feeding frequency affects food consumption, feeding pattern and growth of juvenile yellowtail flounder (Limanda ferruginea). Aquaculture 213: 279-292.

Edds-Walton, P. L., and R. R. Fay. 2003. Directional selectivity and frequency tuning of midbrain cells in the oyster toadfish, Opsanus tau. J. Comp. Physiol. A Sens. Neural \& Behav. Physiol. 189: 527-543.

Edds-Walton, P. L., R. R. Fay, and S. M. Highstein. 1999. Dendritic arbors and central projections of physiologically characterized auditory fibers from the saccule of the toadfish, Opsanus tau. J. Comp. Neurol. 411: 212-238.

Fine, M. L. 1978. Seasonal and geographic variation of the mating call of the Oyster toadfish Opsanus tau L. Oecologia 36: 45-57.

Fine, M. L., and M. L. Lenhardt. 1983. Shallow-water propagation of the toadfish mating call. Comp. Biochem. Physiol. A 76: 225-231.

Gray, G.-A., and H. E. Winn. 1961. Reproductive ecology and sound production of the toadfish, Opsanus tau. Ecology 42: 274-282.

Mensinger, A. F., and S. M. Highstein. 1999. Characteristics of regenerating horizontal semicircular canal afferent and efferent fibers in the toadfish, Opsanus tau. J. Comp. Neurol. 410: 653-676.

Mensinger, A. F., J. P. Carey, R. Boyle, and S. M. Highstein. 1997. Differential central projections of physiologically characterized horizontal semicircular canal vestibular nerve afferents in the toadfish, Opsanus tau. J. Comp. Neurol. 384: 71-85.

Mensinger, A. F., D. J. Anderson, C. J. Buchko, M. A. Johnson, D. C. Martin, P. A. Tresco, R. B. Silver, and S. M. Highstein. 2000. Chronic recording of regenerating VIIIth nerve axons with a sieve electrode. J. Neurophysiol. 83: 611-615.

Mensinger, A.F., K. A. Stephenson, S. L. Pollema, H. E. Richmond, N. Price, and R. T. Hanlon. 2001. Mariculture of the toadfish Opsanus tau. Biol. Bull. 201: 282-283.

Mensinger, A.F., N. N. Price, H. E. Richmond, J. W. Forsythe, and R. T. Hanlon. 2003. Mariculture of the oyster toadfish: juvenile growth and survival. N. Am. J. Aquac. 65: 289-299.

Rabbitt, R. D., R. Boyle, and S. M. Highstein. 2001. Physiology of the semicircular canals after surgical plugging. Ann. N.Y. Acad. Sci. 942: $274-286$.

Rieder, L.E., and A. F. Mensinger. 2001. Strategies for increasing growth of juvenile toadfish. Biol. Bull. 201: 283-285.

Rome, L. C., and A. A. Klimov. 2000. Superfast contractions without superfast energetics: ATP usage by SR- $\mathrm{Ca}^{+}$pumps and crossbridges in toadfish swimbladder muscle. J. Physiol. (Lond.) 526: 279-286.

Ryder, J. A. 1887. Preliminary notice of the development of the toadfish Batrachus tau. Bull. US Fish. Com. 6: 4-8.

Schwartz, F. J., and B. W. Dutcher. 1963. Age, growth and food of the oyster toadfish near Solomons, Maryland. Trans. Am. Fish. Soc. 92: $170-173$.

Smolowitz, R., and R. Bullis. 1997. Bacterial pericarditis: a new disease of toadfish. Biol. Bull. 193: 270-271.

Smolowitz, R., E. Wadman, and H. M. Chikarmane. 1998. Pseudomonas putida infections of the oyster toadfish (Opsanus tau). Biol. Bull. 195: 229-231.

Tang, K. Q., N. N. Price, M. D. O'Neill, A. F. Mensinger, and R. T. Hanlon. 1999. Temperature effects on first-year growth of cultured oyster toadfish, Opsanus tau. Biol. Bull. 197: 247-248.

Thia-Eng, C., and T. Seng-Keh. 1978. Effects of feeding frequency on 
the growth of young estuary grouper, Epinephelus tauvina (Forskäl), cultured in floating net cages. Aquaculture 14: 31-47.

Wenuganen, S., R. Bullis, R. Smolowitz, and E. Barbieri. 1997. Identification of toadfish-pathogenic bacteria based on a comparative molecular approach. Biol. Bull. 193: 269-270.

Wilson, C.A., J. M. Dean, and R. Radtke. 1982. Age, growth rate and feeding habits of the oyster toadfish, Opsanus tau (Linnaeus) in South Carolina. J. Exp. Mar. Biol. Ecol. 62: 251-259.

Winn, H. E. 1972. Acoustic discrimination by the toadfish with comments on signal systems. Pp. 361-385 in Behavior of Marine Animals:
Current Perspectives in Research, Vol. 2: Vertebrates, H. E. Winn and B. L. Olla, eds. Plenum Press, New York.

Young, I. S., and L. C. Rome. 2001. Mutually exclusive muscle designs: the power output of the locomotory and sonic muscles of the oyster toadfish (Opsanus tau). Proc. R. Soc. Lond. B Biol. Sci. 268: 1965-1970.

Young, I. S., C. L. Harwood, and L. C. Rome. 2003. Cross-bridge blocker BTS permits direct measurement of SR $\mathrm{Ca}^{2+}$ pump ATP utilization in toadfish swimbladder muscle fibers. Am. J. Physiol. Cell Physiol. 285: C781-787. 